\title{
ESTADO SOCIAL COMO FÓRMULA EN LA CONSTITUCIÓN CHILENA*
}

\section{ChRISTIAN VIERA ÁLVAREZ**}

RESUMEN: El Estado social es una fórmula política-constitucional que se desarrolla principalmente tras la Segunda Guerra mundial. No es una mera declaración programática sino que a partir de su enunciado, la construcción de la sociedad debe encarnar las exigencias que suponen una preocupación que va más allá de la asistencialidad. A pesar de las dificultades y desafíos que se imponen al Estado social, la problemática que le dio origen sigue latente. Si bien es cierto que la economía, su lenguaje y códigos han tratado de explicar y desarrollar todos los fenómenos de la vida en común, el Estado social no solo no ha perdido eficacia sino que es necesario para responder a los desafíos actuales en Chile, especialmente en materia de igualdad y preocupación por los sectores menos aventajados de la sociedad.

PALABRAS CLAVE: Estado social - estabilidad política - nueva Constitución - deliberación - derechos sociales.

\section{The Welfare State as a FORMUla in THE CHILEAN CONSTITUTION}

\footnotetext{
ABSTRACT: The Welfare State is a politic-constitutional formula developed after World War II. It is not a mere statement, but from its statement, the building of the society must embody the requirements that are a concern which goes beyond assistance. Despite the difficulties and challenges that are placed upon the welfare state, the problem that gave it its origin remains latent. While it's true that economy, its language and codes have attempted to develop and explain all the phenomena of everyday life, the welfare state has not declined, but it is necessary and vital to

* $\quad$ Este artículo es parte del Convenio de desempeño UVA N²1298, de la U. de Valparaíso. Fecha de recepción: 27 de marzo de 2014.

Fecha de aceptación: 27 de mayo de 2014.

** Doctor en derecho. Profesor e investigador Escuela de Derecho-Universidad de Valparaíso (CHILE). Correo electrónico christian.viera@uv.cl
} 
respond to current challenges in Chile, particularly on equality and concern for the less advantaged sectors of society.

KEY WORDS: Welfare State - crisis - political stability - new Constitution - deliberation - social rights

Sumario: 1. Introducción; 2. Breve historia de su conceptualización; 3. Acerca del contenido del Estado Social; 4. Hacia una reformulación del Estado social; 5. Algunos comentarios finales.

\section{1) INTRODUCCIÓN}

En 2014 ha asumido la presidencia de la República Michelle Bachelet Jeria. Su programa de Gobierno (2014-2018) descansa en tres pilares: reforma tributaria, reforma educacional y nueva Constitución ${ }^{1}$. El programa señala que "la idea que recorre el texto actual, aún con las modificaciones que se le han efectuado, está sustentada en una desconfianza a la soberanía popular; de allí las diversas limitaciones a la voluntad popular mediante los mecanismos institucionales de contrapesos fuertes a dicha voluntad, siendo el ejemplo más evidente el mecanismo de los quórum contramayoritarios para la aprobación y modificación de las leyes importantes. Ello no es propio de un sistema democrático; contribuye a la deslegitimación del sistema político; y actualmente constituye un freno al desarrollo del país, y a su gobernabilidad" 2 . Por lo mismo, en el evento de llevar a cabo un proceso de cambio constitucional, el nuevo texto según informa el mismo programa, descansará en ciertos cimientos: derechos humanos, garantías, deberes, sistema político y una referencia final al mecanismo de elaboración y aprobación de la nueva Constitución ${ }^{3}$. En los diferentes pilares se observan novedades que inscribirán esa Constitución en el horizonte de una democracia moderna propia de occidente.

En lo que concierne a este trabajo, quisiera abordar lo relativo al Estado social. El programa señala que "en la Constitución Política se deberá reconocer bajo esta cláusula [Estado social y democrático de derecho] que el Estado no solo es un sistema de potestades, sino un conjunto de deberes de 'buen Gobierno' y de satisfacción de necesidades públicas que son consustanciales a la legitimidad misma del Estado y del Poder. Se funda en la dignidad, libertad e igualdad de las personas, así como los principios

Véase Programa de Gobierno Michelle Bachelet [2014-2018] (2013). Disponible en http://michellebachelet.cl/programa/ [fecha de visita, 26 de marzo de 2014].

Programa de Gobierno Michelle Bachelet (2013) 30

Programa de Gobierno Michelle Bachelet (2013) 30-35. 
participativo, pluralista y de solidaridad. Se trata, ante todo, el Estado social de un Estado de Derecho, fundado en el principio de legalidad y en el respeto de derechos fundamentales, de suerte que la fuente y medida de toda autoridad sea el Derecho mismo. El Estado Social es un Estado democrático, en que el poder electoral reside en el pueblo y su ejercicio se verifica en el poder a través de instituciones, procedimientos y técnicas representativas y participativas. Finalmente, el Estado social es un Estado de garantías, que protege el goce efectivo de derechos económicos, sociales y culturales" $"$.

Muchas Constituciones, en Europa y Latinoamérica han definido sus modelos de Estado como un Estado social, agregando calificativos de democrático o de derecho. Esta definición expresa de la sociabilidad del Estado ¿qué significa? ¿Cómo se traduce en la práctica? El presente artículo contiene unas notas sobre el Estado social, su aporte en la configuración de una sociedad democrática, como también una propuesta de reformulación, a fin que pueda constituirse en material reflexivo frente a la necesaria redefinición político-constitucional del Estado de Chile.

\section{2) BREVE HISTORIA DE SU CONCEPTUALIZACIÓN}

Se ha señalado como precursor de la idea de Estado social a VoN Stein ${ }^{5}$. Sin embargo, Hermann Heller sería el autor de la fórmula Estado Social de Derecho ${ }^{6}$.

Heller postula un Estado de Derecho democrático basado en las relaciones reales de poder, siendo Estado y Derecho los medios de organización de sociedad, en que el Derecho es una técnica de organización social que puede asumir una función al servicio de la transformación de la sociedad, poniendo de relieve la tensión entre la forma jurídica del Estado democrático-social de Derecho y los poderes económicos fácticos que presionan sobre la toma de decisión del poder público ${ }^{7}$.

Programa de Gobierno Michelle Bachelet (2013) 33.

García-Pelayo, Manuel (1989) Las transformaciones del Estado contemporáneo. 2a edición. Madrid: Alianza. 224 pp., p. 14; RitTer, Gerhard (1991), El estado social, su origen y desarrollo en una comparación internacional, Madrid, Centro de Publicaciones Ministerio de Trabajo y Seguridad Social, 300 pp., p. 27.

6 Abendroth, Wolfgang; Forsthoff, Ernst; Doehring, Karl (1986): "El Estado del derecho democrático y social como proyecto político". En Abendroth, Wolfgang: El Estado Social. Madrid, Centro de Estudios Constitucionales, pp. 9-42., p. 20; García-Pelayo (1989) 16; Jimena Quesada, Luis (1997) La Europa Social y democrática de derecho, Madrid, Dykinson. 370 pp., p. 53.

7 Monereo-Pérez, José Luis (2004): “Estudio preliminar. La teoría político-jurídica de Hermann Heller”. En: Heller, Hermann: Teoría del Estado, Granada, Comares. I-XIL pp., p. XI. 
El desarrollo de su pensamiento está condicionado por el problema al que se enfrenta: la crisis de la democracia y del Estado de Derecho, al que considera preciso salvar no solo de la dictadura fascista, sino también del declive al que le ha llevado el positivismo jurídico y los intereses de sectores dominantes, ideas que han convertido al Estado de Derecho en un postulado que, o no significa nada o es incapaz de encarar los dos frentes en que se despliega la irracionalidad: por un lado, la irracionalidad del capitalismo, que provoca un nuevo feudalismo económico en que el Estado formal de Derecho resulta un aplicado cómplice, y por otro, la irracionalidad del fascismo. No renuncia a la idea de Estado de Derecho, sino que lucha por dar a este un contenido económico y social, en que solo el Estado social puede ser una alternativa válida frente a ambas irracionalidades y salvar los valores de la civilización ${ }^{8}$.

Tanto así, que Heller sostiene que "la burguesía está sobresaturada, el pensamiento dominante se hace positivista y la ideología del Estado jurídico toma un matiz formalista. El Estado jurídico significa ahora un Estado en el que la esfera de acción de los gobernantes está limitada por las leyes. No se admite ya la 'metafísica subjetiva' de una justicia. La libertad significa simplemente la seguridad económica de la burguesía contra las intromisiones del Estado en la 'libertad y propiedad de los individuos', no autorizadas por la representación del pueblo. La igualdad no es concretamente lo contrario de la injusticia y la arbitrariedad; no es, por tanto, justicia cualitativa, sino generalidad cuantitativa y lógica"

Los postulados hellerianos están condicionados por su visión política -la socialdemocracia- y la facticidad de su tiempo. Exponiendo las ideas socialistas, no escatima en recurrir a datos e informes que favorezcan la encarnación de sus ideas. V.g. se preocupa de la jornada de trabajo para niños, las condiciones de la vivienda de obreros o la concentración de las explotaciones industriales, todo para mostrar la inhumanidad que produce un sistema capitalista sin consideración de la economía humana ${ }^{10}$. Asimismo, se muestra crítico del capitalismo por la deshumanización que produce y por la pretensión de transformar los criterios económicos como los únicos válidos para explicar el comportamiento humano en la sociedad y para el diseńo de políticas públicas ${ }^{11}$.

Heller defiende la idea de una función para el Estado, pues como función social que nace y se manifiesta por medio de actos de voluntad humana eficaces, la función del Estado es algo que se plantea a la perso-

García-Pelayo (1989) 17.

Heller, Hermann (1985): "Europa y el fascismo". En: Heller, Hermann (1985): Escritos Políticos. Madrid, Alianza, pp. 21-132., p. 30.

10 Heller, Hermann (2004 a) Las ideas politicas contemporáneas. Granada, Comenares. 153 pp., p. 138.

11 Heller, Hermann (2004 b) Teoría del Estado. Granada, Comenares. 330 pp., pp. 244-249. 
na; la función del Estado es dada al hombre por una situación cultural y natural -no meramente natural, como podrían sostener los contractualistas-, como son, v.g., el paso de una sociedad nómade a sedentaria o, en tiempo más reciente, el fenómeno de la división del trabajo ${ }^{12}$. Por ello, sostiene que la función del Estado consiste en "la organización y activación autónomas de la cooperación social-territorial, fundada en la necesidad histórica de un status vivendi común que armonice todas las oposiciones de intereses dentro de una zona geográfica, la cual, en tanto no exista un Estado mundial, aparece delimitada por otros grupos territoriales de dominación de naturaleza semejante" 13 .

Dado que al Estado le asiste una función teleológica y que sin ella, los conceptos de una Teoría del Estado y teoría política aparecen vacíos de significado, Heller postula un modelo de Estado "social" de Derecho, ya que no es la dictadura la solución a la crisis del Estado liberal burgués. El poder de mando de las dictaduras está exento de toda fiscalización, en tanto que en un Estado de Derecho hay controles recíprocos entre las diferentes fuerzas políticas, por lo que la corrupción, fácil de denunciar y controlar en un sistema democrático, es tierra fértil en dictadura, sea por la ausencia de control o la impunidad de los logreros ${ }^{14}$.

A pesar de su contexto, Heller cree que para renovar la cultura y civilización, no solo hay que evitar la dictadura, sino que además se debe relativizar la importancia de la economía, que debe sumisión a las leyes de un Estado de Derecho, puesto que es el sometimiento de los medios a los fines de la vida. Piensa que el futuro de la cultura occidental está amenazado por la dictadura y por el frenesí anárquico de la producción capitalista, que no deja tiempo a los trabajadores, ni ocio y oportunidad a los intelectuales para el desarrollo de una actividad cultural creadora. De ahí el dilema que se plantea para sus tiempos: dictadura fascista o Estado Social de Derecho' ${ }^{15}$.

Contemporáneo a Heller y desde una tradición diferente a la que impera en Europa continental, en el gobierno del Presidente Roosevelt se implementaron una serie de medidas económicas que suponen una intervención directa del Estado para la superación de la crisis económica.

Tras la Primera Guerra y hasta 1929 se produce un gran desarrollo económico en muchos países y, como no, en EE.UU. Sin embargo, los niveles de producción alcanzados no eran equivalentes a los niveles de

12 Heller, Hermann (2004 b) 231-234. Para el contractualismo y su postulado naturalista, Hobbes, Thomas (1999) Tratado sobre el ciudadano. Traducción de Joaquín Rodríguez. Madrid, Trotta. 205 pp., pp. 14-30.

13 Heller, Hermann (2004 b) 235.

14 Heller, Hermann (2004 b) 235; Heller, Hermann (1985): “¿Estado de Derecho o Dictadura?”. En: Heller, Hermann: Escritos Políticos. Madrid, Alianza, pp. 283-301, pp. 292-294. Heller, Hermann (1985) 300-301. 
consumo. El "viernes negro" se produce el crack bursátil en Wall Street e inaugura una época de crisis internacional que afectará a todos los sectores productivos, generando altos niveles de cesantía y caída de precios y producción $^{16}$. Frente a esta situación de crisis, Roosevelt propone un new deal, que supone una mirada a la acción del Estado en relación a los negocios y la economía lo que significará la elaboración de una declaración de derechos económicos y an economic constitutional order, es decir, un orden económico constitucional, una Constitución Económica ${ }^{17}$.

Sin embargo, este cambio en la política económica impulsado por el Estado encontró una fuerte resistencia, puesto que el Tribunal Supremo de EE.UU. se pronuncia en ocho ocasiones en contra del new deal, argumentando que las funciones del Congreso en la Economía eran limitadas y que muchas de las medidas que emanan del plan económico suponen un menoscabo del derecho de propiedad, el que se encuentra reconocido en la Constitución y no puede ser lesionado por el legislador ${ }^{18}$.

Con todo, lo relevante de las políticas del Gobierno de Roosevelt manifiestan que, a pesar de los condicionamientos históricos y políticos que imprimen el carácter liberal de EE.UU., frente a una situación de crisis que afecta seriamente a importantes sectores de la comunidad, la intervención del Estado resulta decisiva para la superación; deben callar los dogmas y dar paso a un sistema operativo que permita encarnar los principios de libertad e igualdad para que esos principios no sean meros formalismos.

La constitucionalización del Estado Social se realiza por primera vez en 1949.

Es menester recordar que, una cosa es la constitucionalización de la fórmula y otra la consagración en la Constitución de los derechos sociales. Sobre esto último, la primera Carta que consagra derechos sociales es la Constitución mexicana de 1917 (arts. 3, 27, 123). Le siguen la Constitución alemana de 1919 (de Weimar) y, tiempo después, la Constitución española de 1931.

La Ley Fundamental de Bonn -Constitución de la República Federal Alemana (RFA) - en su art. 20.1 definía a la RFA como "un Estado federal democrático y social" y el art. 28.1 señala que "el orden constitucional de los Länder deberá responder a los principios del Estado de Derecho republicano, democrático y social". Por su parte, la Constitución italiana

\footnotetext{
16 Rubio Lara, María Josefa (1991) La formación del Estado Social. Colección. Madrid. Tesis doctorales Ministerio de Trabajo y Seguridad Social. 491 pp., p. 112.

17 Roosevelt, Franklin (1999) Great Speeches, New York, Dover Publications. 176 pp., p. 25. No deja de llamar la atención que un liberal como Roosevelt hable de Constitución Económica, dado que significa intervención del Estado en la marcha de la economía y una limitación de la libertad de los individuos. Rubio Lara (1991)128-129.
} 
de 1947 ya esbozaba la idea en sus arts. 1 y 2, pues dicen que "Italia es una República democrática fundada en el trabajo (art. 1) y "la República reconoce y garantiza los derechos inviolables del hombre, ora como individuo, ora en el seno de las formaciones sociales donde aquel desarrolla su personalidad, y exige el cumplimiento de los deberes inexcusables de solidaridad política, económica y social" (art. 2). Con posterioridad, otros Estados han seguido el mismo camino trazado por la Ley Fundamental de Bonn: Portugal (art. 2) o España (art. 1.1).

Lo esencial del Estado Social consiste en que el orden existente (el modelo capitalista liberal) no se reconoce como justo en principio, ni tampoco se admite que la sociedad, como si fuera autónoma, esté sustraída a la intervención estatal ${ }^{19}$. El nuevo Estado, apoyado por la idea intervencionista, va a trabajar prestando asistencia a los más débiles y conformando la vida social. Lejos de inhibirse en la actividad económica, ahora participa activamente como un actor más y como autoridad que controla, planifica e incluso corrige los desequilibrios económicos. De lo dicho cabe extraer una conclusión: mientras que la concepción liberal supuso la separación formal entre Estado y sociedad, el Estado social de derecho va a terminar con esta separación, pues el Estado intervendrá como principal actor en la sociedad - y por consiguiente en la vida económica ${ }^{20}$.

\section{3) ACERCA DEL CONTENIDO DEL ESTADO SOCIAL}

El frágil desarrollo social del siglo XIX y los efectos en la vida de las personas, favorecen la emergencia del Estado social, con énfasis distintos a los propuestos por el Estado liberal; se inicia una progresiva conciliación entre intereses de trabajadores, sectores productivos y autoridad estatal, lo que deriva en la consagración de iniciales regulaciones legislativas en derecho del trabajo desde comienzos del siglo XX. Al mismo tiempo, desde la perspectiva política, el Estado social se vislumbró como una fórmula que busca el logro de la paz social y la estabilidad política, la que únicamente se podía fundar en la justicia social ${ }^{21}$.

Se produce una transformación en cuanto al papel que debe cumplir el Estado en la sociedad. Ya no se trata solo de la defensa de los derechos burgueses clásicos, sino que a partir de la premisa que no es posible un

19 Ballesteros, José Manuel (1980): "Los principios básicos de la Constitución (I): El estado Social y democrático de Derecho". En: Estudios sobre la Constitución española de 1978. Valencia, Universidad de Valencia. pp. 37-44, p. 41.

20 Ojeda Marín, Alfonso (1990) El contenido económico de las Constituciones modernas. Madrid. Instituto de Estudios Fiscales. 328 pp., p. 21

21 Jordán Díaz, Tomás (2006): "La protección de los derechos sociales: modelos comparados de tutela jurisprudencial (Espańa y Chile)”. En: Colección de Investigaciones Jurídicas, № 10. Santiago. Facultad de Derecho, Universidad Alberto Hurtado. 502 pp., p. 19. 
ejercicio real de la libertad si su establecimiento y garantías formales no van acompañadas de condiciones mínimas de existencia, el Estado deviene en distribuidor de prestaciones sociales de diversa índole ${ }^{22}$. Como señala García-Pelayo, "mientras que en los siglos XVIII y XIX se pensaba que la libertad era una exigencia de la dignidad humana, ahora se piensa que la dignidad humana (materializada en supuestos socioeconómicos) es una condición para el ejercicio de la libertad"23.

Reconociendo esta mutación situacional del Estado, es necesaria una prevención. La fórmula Estado social, con defensores y críticos, tiene el carácter de cláusula abierta, por lo mismo, la determinación de su contenido material no es una cuestión ajena a discrepancia temporal y/o espacial. Esta fórmula está presente en algunas Constituciones, pero incluso en esas Cartas no es pacífico el debate sobre su comprensión sustantiva. Por ello no he querido titular el epígrafe con un categórico "contenido de la cláusula" sino más bien con un tímido "acerca..." que permite el tanteo prudente de un terreno que no solo puede presentarse resbaladizo, sino que también escarpado.

El Estado Social es aquella figura política que supone que los poderes públicos (principalmente la Administración) asumen la responsabilidad de otorgar a la generalidad de los ciudadanos las prestaciones y servicios adecuados para la satisfacción de sus necesidades vitales, es decir, vela por lo que la doctrina alemana ha denominado "procura existencial" 24 . También se ha definido como una serie de disposiciones legales que dan derecho a los ciudadanos a percibir prestaciones de seguridad social y contar con servicios estatales organizados en una variedad de situaciones de necesidad y contingencia ${ }^{25}$.

De ambas aproximaciones al fenómeno del Estado Social destacan, al menos, dos rasgos comunes. Por un lado, el Estado se presenta como un prestador de servicios y de otro, esos servicios se otorgan en la medida que exista una necesidad vital insatisfecha.

El Estado, mirado desde esta perspectiva, centra sus funciones en la búsqueda y realización de la justicia distributiva y la justicia material, con un Estado gestor al servicio de los ciudadanos. Por tanto, las medidas concretas estarán encaminadas a la seguridad de aspectos vitales de la sociedad, que no solo tienen que ver con Defensa, sino que también con la prevención y sanción del delito o el cuidado del medio ambiente.

\footnotetext{
22 GonzÁlez Moreno, Beatriz (2002) El Estado Social. Naturaleza juridica y estructura de los derechos sociales. Madrid. Civitas-Universidad de Vigo. 263 pp., pp. 45-46.

García-Pelayo (1989) 26.

Pérez-Luño, Antonio (2004) Los derechos fundamentales. 8a edición. Madrid, Tecnos. 233 pp., p. 193.

25 Offe, Claus (1988) Partidos politicos y nuevos movimientos sociales. Madrid. Editorial Sistema. 265 pp., p. 74.
} 
Asimismo, caben prestaciones como la fijación de un salario mínimo, la protección del empleo, la protección de la salud, el acceso a la vivienda, medidas para mejorar la distribución de la riqueza, la formación de capital cultural en las distintas clases sociales, etc, siendo lo relevante no tanto la implementación de políticas de nacionalización de los medios de producción, cuanto una justa distribución de lo producido llevada a cabo por la utilización para ese fin de la potestad impositiva fiscal ${ }^{26}$.

Offe señala que la aceptación del Estado Social en los países de occidente fue compartido por la mayoría, independiente de la fuerza política que detentara el poder, hasta que se produjo una primera gran crisis económica y el cambio de paradigmas políticos en importantes países. Se refiere a la crisis por el precio del petróleo en la década del setenta y la llegada de Thatcher y Reagan al poder en Reino Unido y Estados Unidos. Esta aceptación se fundaba en que las principales economías de los países industrializados eran prósperas y desarrolladas y, además, en que un esquema estatal de esta naturaleza supone estabilidad política y menor agitación social, pues atenúa el conflicto entre clases ${ }^{27}$.

Sin embargo, aunque es posible señalar medidas operativas que encarnen un modelo de Estado Social, por el carácter abierto de la cláusula, aparecen innumerables interrogantes para comprender su contenido. Por de pronto, cuáles son las necesidades básicas que deben ser satisfechas, en qué consiste la "procura existencial", las disposiciones constitucionales que plasman las matrices del Estado Social son imperativas o más bien obedecen al deseo del Constituyente pero sin exigencia práctica, es una cláusula pacífica o ambigua. Si bien estas no son todas las preguntas, ayudan a centrar un problema de la definición de Estado Social: el de su interpretación.

Señala BöCKEnFöRde que la apelación a lo social derivada del concepto de Estado Social de Derecho es una apelación de carácter general, viva y abierta, no existiendo en la actualidad acuerdos sobre en qué medida se pueden estructurar elementos sociales en una Constitución sin que se pierdan elementos esenciales del Estado de Derecho, ni tampoco sobre cuáles son los elementos sociales estructurales que deben ser considerados ${ }^{28}$.

A su vez, como postula Rosanvallon, el Estado reposa en un programa ilimitado que consiste en liberar a la sociedad de la necesidad y el riesgo. Es ilimitado, porque es el traslado a lenguaje económico del problema político de la búsqueda del bienestar, en que además existe el problema que las palabras necesidad, satisfacción y bienestar son vagas y confusas. Por de pronto, necesidad oscila entre el concepto de superviven-

\footnotetext{
26 García-Pelayo (1989) 29-33; González Moreno (2002) 46-47; Pérez-Luño (2004) 193.

27 OfFe, Claus (1988) 72-73.

28 BöcKenförde, Ernst-Wolfgang (2000) Estudios sobre el Estado de Derecho y la democracia. Madrid. Trotta, 208 pp., p. 37.
} 
cia y abundancia, en que al Estado (protector) correspondería la garantía de la supervivencia y una abundancia mínima (Estado providencia), pero en qué consiste ese mínimo: es un concepto histórico y evolutivo, mas el sistema de necesidades se confunde con la dinámica social ${ }^{29}$.

Ahora bien, es imposible dar respuesta categórica a los planteamientos que surgen por la cláusula del Estado social, aunque es posible realizar una interpretación que se mantenga próxima a la realidad, con el riesgo, claro está, de rebajar el debate constitucional a uno de impronta políticocotidiano. Siguiendo a BENDA, la búsqueda de la justicia social es esencial a toda política, de ahí que toda política presuma de sí misma de ser conforme al Estado social, con la conciencia que al carácter 'social' se atribuyan diversos objetivos ${ }^{30}$.

Por ello, la cláusula Estado social se puede interpretar de diversas maneras. Una manera es asociarla a los problemas derivados de la cuestión social (protección a los pobres y necesitados). Pero también puede ser lo social un rechazo al individualismo imperante, de lo que resulta el esfuerzo por compensar intereses antagónicos con la solidaridad. O, en tanto que ceden los intereses individuales, se plantee la situación social como la más importante o, al revés, prestar atención al individuo que, antes que todo es ser social. Con todo, es denominador común de las posturas la relación entre individuo y comunidad.

Según Benda, en la doctrina y jurisprudencia alemana es posible constatar indicios de acuerdo para interpretar la cláusula del Estado social. Una decisión adoptada por el Tribunal Constitucional y el Tribunal Supremo Federal ha concebido esta cláusula como un mandato constitucional al legislador para que se interese por los asuntos sociales. También el Tribunal Federal de lo social interpreta este postulado no solo como exigencia programática, sino como habilitación al legislador para que configure un orden social orientado al establecimiento y garantía de la justicia social, como también a la eliminación de situaciones sociales de menesterosidad. Por su parte, el Tribunal Federal de lo Contencioso ha establecido que este parámetro de interpretación está directamente relacionado con la garantía de la dignidad humana. Lo anterior, no impide, en opinión del autor, que la interpretación hecha por la jurisprudencia constitucional se muestre cauta para aplicar materialmente el postulado, tanto así que, acogiendo la opinión de un voto de minoría acuse una cierta timidez para recurrir al principio del Estado Social en el juicio de constitucionalidad $^{31}$.

\footnotetext{
29 Rosanvallon, Pierre (1981) La crise de l'Etat-providence. Paris. Editions du Seuil. 194 pp., pp. 33-34.

30 Benda, Ernst (2001) "El estado social de Derecho". En: Benda, Ernst et al., Manual de Derecho Constitucional. 2a edición. Madrid. Marcial Pons. Pp. 487-559, p. 522.

31 Benda, Ernst (2001) 525.
} 
Si bien la apertura de la cláusula no debe impedir que en su interpretación puedan tener cabida variedad de posiciones, es necesario un requisito: se debe hacer un esfuerzo para su concreción material. El mismo Benda dice que "la democracia no depende menos del consenso en las cuestiones fundamentales que de la diversidad de las opiniones. La cláusula del Estado social... sirve para promover un tal acuerdo"32.

A pesar de las dificultades que entrańa la interpretación de esta fórmula, es razonable la tesis propuesta por García-Pelayo en cuanto a que la distribución ha sido siempre un concepto clave de la estructura y función del Estado, si bien cambian sus modalidades y contenido; no hay Estado sin distribución de poder entre gobernantes y gobernados y en el orden económico procede a la distribución de recursos económicos nacionales en recursos fiscales y en recursos a disposición de las personas ${ }^{33}$.

Por tanto, la interpretación del contenido material del Estado social puede variar a lo largo del tiempo, pero siempre quedando un cierto $m i$ nimum, en que los problemas de financiamiento de los derechos sociales no pueden significar el grado cero de vinculación jurídica de los derechos fundamentales sociales. Y, no debe olvidarse que tras esta cláusula existe una determinada opción política-ideológica que, en un sistema democrático, dependerá de la ciudadanía ratificarla o mudarla ${ }^{34}$.

Como señalé, es compleja la determinación del contenido del Estado social. Y no solo eso; esta cláusula no está exenta de críticas ni de crisis, no obstante, excede los propósitos de este trabajo revisar ambas perspectivas, por lo que en lo siguiente, me detendré en el significado de una cláusula sobre estado social en una nueva Constitución chilena ${ }^{35}$.

\section{4) HACIA UNA REFORMULACIÓN DEL ESTADO SOCIAL}

¿Hay porvenir para el Estado social? Parece que sí, pero con modificaciones a la idea original. Por de pronto y compartiendo el diagnóstico de Offe, el Estado social es una estructura irreversible, cuya abolición

\footnotetext{
32 Benda, Ernst (2001) 528.

33 García-Pelayo (1989) 34.

34 Balaguer Callejón, Francisco (2002). "El estado Social y democrático de derecho, alcance y vinculación de la cláusula del Estado Social”. En: Monereo Pérez, José Luis: Comentario a la Constitución Socio-Económica de España. Granada. Comenares, pp. 89-113, p. 101. En la misma línea véase HäBerle, Peter (2002) Pluralismo y constitución. Madrid. Tecnos. 295 pp., pp. 201-209.

35 Existe abundante literatura para abordar la crisis del Estado social, como también detractores de la fórmula. Para un análisis más detallado de esta discusión, y especialmente por las referencias bibliográficas, véase Viera Álvarez, Christian (2013) Libre iniciativa económica y Estado Social, Santiago, Thomson Reuters. 417 pp., pp. 35-53, como también Martínez DE Pisón, José (1994) "La crítica neoliberal al Estado Social. Un resumen y una valoración”. En: Doxa, N¹5-16, pp. 243-270.
} 
exigiría la abolición de la democracia política, los sindicatos y el sistema de partidos, lo que implica cambios dramáticos en la estructura de la sociedad. Pero no solo eso. El neoliberalismo y su propuesta de Estado mínimo, a pesar de la sencillez y razonabilidad de sus postulados, no es la solución para la crisis. Sin una política de subsidios, sea a la vivienda, educación o salud, así como un sistema de seguridad social obligatorio, el funcionamiento del sistema económico sería inconcebible, ya que la desaparición de las matrices de un Estado social abandonaría a la realidad social a un escenario de conflicto explosivo y crisis de la convivencia ${ }^{36}$.

Al mismo tiempo, el Estado social no solo ha sido un catalizador de la paz social sino que esta estructura de Estado ha asegurado durante decenios un nivel de vida y una satisfacción de las necesidades básicas de los ciudadanos que difícilmente podrá encontrarse un ejemplo análogo al éxito de esta experiencia, porque el Estado social ha favorecido el aumento del capital humano, una mejor distribución y transferencia de rentas entre diversas clases sociales, junto a una estabilidad política que favorece la cohesión, ya que las prestaciones de bienestar operan como elemento compensador a la competencia pura y al carácter ganador-perdedor que suscita el mercado ${ }^{37}$.

Mas, cuáles son las líneas a priorizar a fin que el Estado social no desaparezca. Son varias las dimensiones que debería abordar, pero adelanto que el futuro del Estado social no pasa solo por un desarrollo de su carácter prestacional, necesario por cierto, sino que su profundización está asociado al estado de derecho y sistema democrático; por lo mismo la dimensión no es solo jurídico-económica sino que también política.

El Estado Social clásico, que se construye con un fuerte componente legal y administrativo, se desarrolla bajo una lógica inclusiva y excluyente. Es cierto que se producen intervenciones en favor de sectores sociales deprimidos e incluso postergados de beneficios sociales; sin embargo, "son sobre todo aquellos grupos organizados, capaces de presionar corporativamente en las instituciones estatales, los principales beneficiarios de las políticas sociales" 38 . De ahí que no extrañe el peligro a una dimensión clientelar del Estado Social, "transformándose la compleja problemática del trabajador por la de simple consumidor y la del ciudadano por la de cliente del Welfare State" 39 .

\footnotetext{
36 Offe, Claus (1988) Contradicciones en el Estado del Bienestar. Madrid. Alianza. 309 pp., pp. $141-142$.

37 Ojeda Marín, Alfonso (1993) Estado social y crisis económica. Madrid. Editorial Complutense. 124 pp., p. 42.

38 Pisarello, Gerardo (2001) "Del Estado Social legislativo al Estado Social constitucional: por una protección compleja de los derecho”. En : Isonomía $\mathrm{N}^{\circ} 15$, pp. 81-107., p. 85.

39 De Cabo Martín, Carlos (1997), Contra el consenso. Estudios sobre el estado constitucional y el constitucionalismo del estado social, México D.F. UNAM, Instituto de investigaciones jurídicas, 393 pp., p. 226.
} 
En la misma línea, Gómez apunta a que la reestructuración del Estado social debe hacerse en una doble dirección: desde arriba y desde abajo. Lo primero significa que se debe actuar sobre los propios objetivos del Estado social, sus recursos e instituciones, de manera que se adecuen a las necesidades actuales de reestructuración del capitalismo, buscando una mayor eficacia, descentralización y flexibilidad en la actuación del Estado. Lo segundo hace referencia a una profundización de la sociedad civil en la configuración y objetivos del bienestar social. No se cuestiona tanto el papel del Estado, sino que propone nuevos criterios de orientación: una mayor participación de la sociedad en la organización de la red de protección social, en que las personas en vez de ser receptores de la protección del Estado deben comenzar a buscar alternativas para conseguir protección e integración social ${ }^{40}$.

Para llevar a cabo este propósito, se incluyen la conservación de la intervención estatal en sectores claves de la economía, compromiso del capital de favorecer un crecimiento productivo que favorezca la generación de puestos de trabajo y la de encontrar un modo para vincular los beneficios del capital con la política salarial, proponiendo como ejemplo el aumento de la intervención social en los mecanismos de reinversión y reproducción del capital ${ }^{41}$.

Con todo, Gómez cree que la rearticulación del Estado social pasa también por una reaparición del principio de la solidaridad, ya que una redefinición del sistema capitalista en menos solidario conduce a una marginación de los sectores empobrecidos, marginación que, si bien, puede no desembocar en un conflicto social abierto, ni poner en peligro el nuevo modelo de Estado, una fórmula que aísla la solidaridad solo podrá ser disfrutado por un puñado de miembros de la comunidad, generando una sociedad menos solidaria ${ }^{42}$.

Por lo tanto, Estado Social no puede reducirse a su carácter prestacional sino que debe estar en estrecha conexión con su complemento "democrático". Pero no podemos entender la democracia en términos meramente formales o plebiscitarios. No cabe duda de la importancia del sufragio, pero sabemos que los procesos electorales no agotan el sistema. Claro, podemos tener una claridad conceptual sobre la democracia, sin embargo, en no pocas ocasiones gobiernos concretos limitan sus procesos democráticos a las elecciones y una deliberación modesta en los Congresos Nacionales. Pisarello encarna con lucidez esta problemática: "lo que se promueve en la mayoría de los casos es una concepción delegativa y plebiscitaria de la democracia reducida a una periódica competición

\footnotetext{
40 Gómez, Jesús María (1995) “El Estado del bienestar y el reto de la solidaridad”. En: Anales de estudios económicos y empresariales, $\mathrm{N}^{\circ} 10$ Universidad de Valladolid, pp. 255-276, p. 268. Gómez (1995) 269.

42 Gómez (1995) 271-272.
} 
electoral encargada de legitimar la aplicación decisionista de programas que se dirigen a eliminar los controles jurídicos a los poderes privados y a limitar en cambio las posible garantías de los derechos sociales impulsadas tanto en dese política como en los espacios autónomos surgidos en el seno de la sociedad" 43 .

Profundizando la idea, Lovera a propósito del derecho a protesta señala "una democracia representativa resulta posible solo allí donde la autorización va acompańada de un diálogo fecundo entre representantes y representados. El voto solo logra dar cuenta del primero de esos momentos (la autorización), pero es insuficiente para dar cuenta de las complejidades que demanda el diálogo democrático... En efecto, el mecanismo de elecciones es muy tosco (en general votamos respondiendo a eslóganes) e impide que las preocupaciones más específicas sobre una determinada decisión política puedan expresarse" 44 .

Por lo tanto, el Estado Social, debe transitar de su carácter prestacional (y formal) a uno que se funde en un constitucionalismo como "instrumento de autocontención política, económica, de desaceleración de la acumulación de poderes y de reconstrucción de la solidaridad entre los miembros más vulnerables de la sociedad" 45 . De hecho, el Estado Social no es una reacción al Estado liberal; es su necesario complemento, ya que existe un nexo entre democracia social y democracia política (liberal), entre derechos políticos y sociales, en la medida en que "existe un nexo axiológico, que consiste en el hecho de que la satisfacción de los derechos sociales asegura los 'prerrequisitos' de la democracia política" ${ }^{46}$. Claro, porque en las sociedades contemporáneas, interdependientes, la conexión entre derechos "representan un factor indispensable de cohesión social, y, por ello, de ese tanto de igualdad material, de reconocimiento recíproco, de solidaridad e identidad colectiva que es asimismo un presupuesto esencial de la democracia política" 47.

Tratándose del Estado de Chile, desde la perspectiva de una democracia social existe una deuda en relación al rol del Estado ${ }^{48}$. Y, a pesar de

Pisarello (2001) 90.

Lovera Parmo, Domingo (2014), Derecho a la protesta en la Constitución de 1980 (de 1989 $y$ de 2005), inédito, pp. 1-15, p. 10.

Pisarello (2001) 92.

Ferrajoli, Luigi (2011), Principia Iuris, vol. 2. Teoría de la democracia, Madrid. Trotta. 676 pp., p. 383.

FerRajoli (2011) 383-384.

No es del caso examinar la crisis actual de nuestro modelo de desarrollo, pero algunas luces dan autores que es necesario revisar, especialmente Mayol, Atria o Fuentes. Sobre el punto, véase Fuentes Saavedra, Claudio (2012) El Pacto. Santiago. Ediciones Universidad Diego Portales, 259 pp.; Mayol, Alberto (2012), El derrumbe del modelo Santiago, LOM, 166 pp.; Mayol, Alberto (2012), No al lucro, Santiago, Debate, pp. 392 pp.; Atria, Fernando (2013), Veinte años después, Neoliberalismo con rostro humano, Santiago, Catalonia, pp. 1259 pp.; Atria, Fernando et al (2013), El otro modelo, Santiago, Debate, 389 pp. 
la relativización operativa a los paradigmas del neoliberalismo descarnado impuesto en Chile hasta 1990, persisten los desafíos desde la perspectiva de una sociedad con mayores niveles de cohesión. Ha habido progresos, no cabe duda; en términos de Atria, el neoliberalismo de los últimos veinte años ha adquirido rostro humano, pero sigue siendo el Estado de Chile uno de corte neoliberal ${ }^{49}$.

El tránsito de un Estado neoliberal a uno de corte social no será rápido ni fácil. Reclama intervención del legislador, pero también implementación operativa en la Administración del Estado. Pero reclama, sobre todo, voluntad política. El problema constitucional, por tanto, no solo debe reducirse a lo técnico (la dogmática) sino que especialmente lo normativo (carácter político de la Carta). Y en ese sentido, la deliberación cobra un papel relevante, porque en los procesos de mutación hacia nuevos estadios de configuración en una comunidad, la estabilidad solo se consigue con legitimación social. Por lo mismo, es necesario que un Estado Social se caracterice por la apertura de espacios de participación, que pueden ser por la vía de una democracia directa (plebiscitos, consultas), pero también espacios institucionales de diálogo con mecanismos representativos y efectiva apertura y acceso de los medios de comunicación social. De hecho, uno de los problemas del sistema democrático moderno es la calidad del debate público y la relación con los medios masivos, principalmente la $\mathrm{TV}^{50}$. Si bien, el diagnóstico y su implementación no es garantía de éxito, nada obsta que un Gobierno implemente un programa que tenga como horizonte un Estado social. Como señalan algunos, se trata de pensar estructuras institucionales "que puedan hacer más probable una forma de interacción política en que la mera negociación entre grupos de poder se torne menos frecuente, precisamente porque lo que se vuelve más usual es la deliberación entre ciudadanos acerca del interés general" 51 .

Con todo, ¿qué significa que la cláusula Estado social se encuentre en la Constitución? ¿Se trata de una disposición programática? Para responder a esta pregunta, clave será la aproximación hermenéutica con la que se responda.

Esta cláusula, al figurar en la Constitución, excluye una interpretación radicalmente individualista de los derechos fundamentales, lo que supone "adecuar el disfrute efectivo de los diferentes derechos a las po-

\footnotetext{
49 Un interesante análisis sobre este punto se puede observar en los ejemplos que da Atria para justificar esa tesis. Sobre el punto véase Atria (2013), 40-53.

50 El problema del empobrecimiento del debate político no es nuevo ni propio de nuestro país; hay diagnósticos certeros sobre el punto y lo relacionan con la calidad de la democracia. Un acercamiento a este problema se puede encontrar en Nino, Carlos Santiago (1997) La constitución de la democracia deliberativa. Barcelona, Gedisa, 303 pp., pp. 214-228. Atria, et al. (2013) 107.
} 
sibilidades reales de cada sector de la sociedad, reforzando, sí, unas veces su aprovechamiento en referencia a los sectores menos privilegiados, pero también restringiendo otras el alcance el alcance de esos derechos (función social de la propiedad) en razón de la posición social prevalente de sus titulares" 52 .

La apertura de los conceptos constitucionales unida a una lectura de la sociedad y Constitución dinámica, permite que la interpretación pueda ir adaptándose a las cambiantes circunstancias sociales, políticas o económicas y evitar el peligro de una petrificación del derecho, peligro latente y del que no pocas veces pecan los sistemas jurídicos. Que la realidad social va cambiando no es un descubrimiento copernicano. La dificultad estriba en una lectura adecuada de la realidad y de la necesaria adaptación a los tiempos nuevos.

El sistema jurídico debe manifestarse abierto a esta problemática y generar la flexibilización de los criterios que por tanto tiempo han acompańado el devenir de nuestra sociedad. No es inocuo plantear un determinado modelo de interpretación en vez de otro. Si se bebe de una fuente flexible, las cláusulas abiertas pueden ser determinadas evolutivamente en su contenido material, pero, si la fuente es restringida, se quedará atrapado por la tradición y el momento inicial del pacto, original intent. Y esto con la conceptualización del Estado social, siendo necesario interpretar la fórmula con criterios amplios, extensivos y abiertos a la constante evolución de la sociedad.

Al mismo tiempo, en el actual modelo de desarrollo, no puede sustraerse la comprensión del Estado en clave puramente nacional; la autoconciencia global ha impuesto un nuevo paradigma en que los estados no se bastan a sí mismos sino que se encuentran estrechamente relacionados (y por qué no decirlo, condicionados). Por ello señala Serra que en el próximo futuro será "imposible encontrar una salida a los problemas que lleva consigo el desarrollo del Estado desde una perspectiva puramente nacional. Vivimos hoy ya una época en que se ha desarrollado la conciencia planetaria que pugna por alzarse ante los obstáculos que representan los Estados nacionales" 53 . En este contexto se puede globalizar un modelo de Estado que, a pesar de sus dificultades, ha estado marcado por el éxito. Dice Carmona Cuenca que, si bien es sabido que el bienestar de unos se basa normalmente en las condiciones materiales ínfimas de la mayoría, los mismos postulados que hicieron surgir el Estado social en las sociedades occidentales industrializadas, deben servir para crear un Estado social

52 Garrorena Morales, Ángel (1987) El Estado español como Estado social y democrático de Derecho, El Estado español como Estado social y democrático de Derecho. Madrid. Tecnos. 254 pp., p. 102.

53 Serra, Francisco (1991) "El futuro del Estado social”. En: Olivas, Enrique: Problemas de legitimación en el estado social. Madrid. Trotta, pp. 165-176, p. 174. 
mundial, porque figura de esta naturaleza no solo va en directo interés de las naciones menos desarrolladas sino que también afecta a los países industrializados, pues puede impedir que los graves desequilibrios actuales desemboquen en una crisis generalizada 54 .

¿Llegará ese momento pronto? Difícil saberlo, ya que se trata de un desafío de largo aliento. Sin embargo, hay un camino trazado en otras latitudes, en que los resultados de su implementación pueden verse reflejados en diversos indicadores, v.g. PNUD, PISA, inclusión, desigualdad ${ }^{55}$. Por lo mismo, no se trata de experimentar a partir de lo desconocido, sino que observar las experiencias comparadas que han demostrado que con matrices sociales (y en el marco de economías abiertas), es posible una mejora sustantiva de los indicadores de equidad.

Ha habido enormes progresos en el desarrollo de los derechos sociales en las últimas décadas. No obstante, la realidad mundial no es homogénea sino esencialmente dispar. A pesar de la consolidación de la democracia y el mercado como sistemas político y económico, la fragilidad institucional de muchas naciones, los problemas de corrupción o la distancia cultural no favorecen una inculturación pacífica de los paradigmas del Estado social, porque el problema es complejo y no solo jurídico o económico; es también una cuestión antropológica, religiosa, sociológica y étnica. Y aún más, la implementación de sus postulados supone gran cantidad de dinero, lo que es difícil de obtener en países con economías primarias.

A pesar de las dificultades y desafíos que se imponen al Estado social, la problemática que le dio origen sigue latente. Si bien es cierto que la economía, su lenguaje y códigos han tratado de explicar los fenómenos de la vida en común, el mero orden espontáneo no es el catalizador de una sociedad más igualitaria; el Estado social, con su caminar a tientas, no solo no ha perdido eficacia sino que es necesario para responder a los desafíos sociales, especialmente en materia de igualdad y preocupación por los sectores menos aventajados de la sociedad.

\footnotetext{
54 Carmona Cuenca, Encarnación (2000) El Estado Social de Derecho en la Constitución. Madrid. Consejo Económico y Social. 198 pp., pp. 90-91.

55 Véase OECD (2014), Society at a Glance 2014: OECD Social Indicators, OECD Publishing. Disponible en http://dx.doi.org/10.1787/soc_glance-2014-en [última visita 27 de marzo de 2014], 143 pp., pp. 109-119; Programme for International Student Assessment (2013), PISA 2012 Results in Focus. OECD Publishing. Disponible en http://www.oecd. org/pisa/keyfindings/pisa-2012-results-overview.pdf [última visita 27 de marzo de 2014] 32 pp., p. 5; Programa de las Naciones Unidas para el Desarrollo (2013), Informe sobre Desarrollo Humano 2013. El ascenso del Sur: Progreso humano en un mundo diverso. Nueva York. PNUD Disponible en http://www.undp.org/content/dam/undp/library/corporate/ HDR/2013GlobalHDR/Spanish/HDR2013\%20Report\%20Spanish.pdf [última visita 27 de marzo de 2014] 216 pp., pp. 143-197.
} 


\section{5) LA CLÁUSUla del ESTADo SOCIAL EN LA CONSTITUCiÓN CHILENA}

En la historia constitucional chilena, no es característica la presencia de un rol social para el Estado, salvo la Constitución de 1925, especialmente a partir de las reformas que se introdujeron al derecho de propiedad en la década de los sesenta.

En el caso de la Constitución de 1833, esta se caracterizó por configurar un Estado fuerte y autoritario, pero con un propósito específico: restaurar y mantener el orden institucional. Para lograr ese propósito, el Presidente fue dotado especiales facultades, v.g. declaración del Estado de sitio (art. 82, 20a), que tiene como efecto suspender el imperio de la Constitución en el territorio comprendido en la declaración (art. 161); la autorización de parte del Congreso de facultades extraordinarias al Presidente, sin límites de contenido, sino formales en cuanto a señalar las facultades concedidas (art. $366^{\mathrm{a}}$ ); Presidente irresponsable políticamente mientras dure su mandato y solo podía ser acusado en el año posterior al término de su mandato (art. 83); o la facultad de veto suspensivo a los proyectos de ley aprobados por el Congreso, es decir, si el Presidente desechaba por completo un proyecto de ley, se tenía por no propuesto y no podía volver a discutirse la materia en la misma legislatura ${ }^{56}$. Con todo, es posible encontrar algunos antecedentes sociales, v.g. a las Municipalidades le cabe un rol de promotora de la educación (art. 128 No 2). Más relevante puede ser el art. 153, que señala que "la educación pública es una atención preferente del Gobierno". Sin embargo, no se caracteriza esta Constitución, como es propio del siglo XIX, en manifestar una preocupación por la sociabilidad del Estado.

Tal vez, la Constitución de 1925 es la que más se acerca a una Constitución con componentes sociales, porque tratándose de derechos específicos como la propiedad, a esta le corresponde una función social que no se agota en la utilidad pública o el interés general, ya que también es propio de esta función "el mejor aprovechamiento de las fuentes y energías productivas en el servicio de la colectividad y la elevación de las condiciones de vida del común de los habitantes" (art. 10 No 10 inc. 2).

Al parecer, los cambios que recoge la Constitución de 1925 son reflejo de una creciente democratización y una ingente actividad económica del Estado, generada en gran parte por la industrialización chilena. Por ello, el modelo democrático que se asienta puede ser llamado como democracia social, que se apoya en las masas populares y el reconocimiento de un nuevo concepto del derecho de propiedad que incluye su función social, la introducción de la seguridad social, la indemnización a los des-

56 Sobre el carácter autoritario de la Constitución de 1833 véase PALMA (2002) 45-64. 
poseídos, la instrucción primaria obligatoria y la progresividad de los impuestos $^{57}$.

Para el caso de la Constitución vigente, se advierte la influencia de la filosofía cristiana en el capítulo relativo a las Bases de la Institucionalidad. $\mathrm{Y}$, de hecho, esta presencia es lo que ha llevado a algunos autores a señalar que en Chile se ha producido una recepción del Estado social ${ }^{58}$.

CEA piensa que la Constitución, al ser una Carta completa "ha precisado y ampliado lo que se llama el Constitucionalismo Social, en virtud del cual entre los derechos humanos es fuerza reconocer, proteger y promover los de contenido económico coadyuvantes del bienestar general" 59 . Y una manifestación de esto es el postulado constitucional que asigna al Estado la finalidad de promover el bien común, para lo cual ha de contribuir a crear las condiciones sociales que permitan a todos y cada uno de sus integrantes su mayor realización espiritual y material posible $e^{60}$, sin embargo, reconoce que las normas constitucionales chilenas proclaman imperfectamente el Estado social ${ }^{61}$.

Otro autor, Varela, señala que en la Constitución chilena, "toda interpretación o aplicación neoliberal (del Estado espectador y no actor) traiciona en su fundación el verdadero, cristiano y auténtico sentido de la subsidiariedad. Esta idea capital de la nueva institucionalidad chilena conduce, como lo anhela Juan Pablo II, a la Economía de la Solidaridad" 62 . Lo anterior, porque si bien la empresa privada es impulso-

57 Cristi-Ruiz-Tagle (2007) 429 pp., 115-116. A juicio de Salazar, los cambios en la estructura del Estado son más complejos y obedecen a la irrupción de corrientes nacionalistas, unidas en algún momento a políticas desarrollistas y en otras, lisa y llanamente al populismo. Sobre el punto, Cf. Salazar (1999) 311 pp., 156-166.

58 El autor que ha trabajado más detenidamente este asunto es SolARI, aun cuando es posible encontrar elementos aislados en otros. Sobre el punto, véase Solari (1993b) 122 pp. Asimismo, pueden revisarse las versiones resumidas de ese trabajo: Solari (1997) 11-104; Solari (1993a) 333-344. Al mismo tiempo, Cea (1988) 402 pp; Cea (1983) pp. 7-19, 16; Belmar (1986) 97 pp; Varela (1984) 385-402; Varela (1989) 379-390; Silva Gallinato (2012) 29-48. En este último caso, a pesar de sostener que la Constitución considera un Estado social, su justificación no es muy diferente a la entregada por los autores anteriores.

También podemos señalar a Quintana quien defiende la idea de que en la Constitución se consagra el principio de solidaridad, sin embargo, su reflexión, aparte de breve, se limita a una búsqueda de la palabra solidaridad en diferentes normas de la Constitución para concluir que este principio está consagrado explícitamente (en normas específicas) e implícitamente en las Bases de la Institucionalidad, a pesar de la "dramática ignorancia generalizada de dicho principio como una de las bases de nuestra institucionalidad” (Quintana(1989) 635-638).

CEA (1988) 156.

CEA (1988) 85 .

CEA (1988) 86. Esta opinión es matizada posteriormente por CEA y expresa una opinión crítica frente a la opción tomada por la Constitución en cuanto a los derechos sociales. En la actualidad sostiene que Chile debe avanzar hacia una sociedad estatal equitativa, en la cual la justicia social sea parte de su cultura. Al respecto CEA (2004) 89-91. 
ra del desarrollo, eso no significa que el Estado deba abdicar de su esencial y necesaria función de cautela, con el propósito de superar o atenuar la miseria ${ }^{63}$.

VAREla se basa en utilización de los términos "dignidad" y "bien común” para arribar a esta conclusión. Por de pronto, "para que haya dignidad, es menester de la existencia de cuatro o cinco necesidades vitales básicas y primarias, a saber: abrigo, vivienda, alimentación y educación, además de trabajo. Estas son las condiciones absolutamente mínimas para el desarrollo mental y físico del ser humano" 64 , las cuales, por ser necesidades mínimas que el hombre requiere, el Estado deberá dárselas (junto con otras) a todos sus miembros ${ }^{65}$. Por ello debe existir un equilibrio entre sociedad y Estado, de manera que ninguno de los dos se resienta. "La labor de balance de ambos factores, que en otros términos es el de la libertad y del poder, constituye la piedra angular de una comunidad justa y feliz. Esta es la meta precisamente del Estado Social y Económico de Derecho, y dentro de este, de una auténtica economía social de mercado" 66 .

Si bien las opiniones son pocas, no explícitas en cuanto a la consideración del Estado de Chile como Estado social y más bien reflejo de un anhelo, no es más vasto el panorama doctrinal al respecto. Como señalé, quien ha afirmado expresamente que en Chile la Constitución vigente ha asumido el Estado social ha sido Solari.

Para defender su tesis, lo primero que realiza es recoger las normas de la Constitución en las cuales se encontraría el mandato social y económico dirigido al Estado, entre las que destaca el art. 1 de la Constitución reposando su argumento en la dignidad humana y la promoción del bien común ${ }^{67}$.

Por de pronto, señala que este artículo goza del privilegio de constituir una verdadera pauta de interpretación de toda la Constitución y, aunque en el mismo Capítulo I hay diferentes vertientes ideológicas, estas aparecen en forzosa relación, dando lugar a preeminencias, modulaciones y subordinaciones, ya que las normas constitucionales conforman un sistema dotado de jerarquía, en donde las que se ubican en el Capítulo I pertenecen a un primer grupo que preside todas las demás, por lo que las ideas que concurren en la Constitución no concurren parejamente, sino

\footnotetext{
VARELA (1989) 383.

VArela (1984) 391. Cursivas en original.

VARELA (1984) 401.

VArela (1989) 384. Incluso señala que si el rol del Estado es interpretado como de abstención en la vida social, "es un aspecto ultraliberal y que conlleva al individualismo, que tantas nefastas influencias anticristianas ha producido este siglo" (VARELA (1989) 385).

67 Solari (1993) 68-71. También señala otras normas en que ese mandato estaría presente, v.g. art. 100 inc. 2 (actual art. 111 inc. 2); 104 inc. 2 (actual art. 115 inc. 1); art. 107 inc. 4 (actual art. 118 inc. 4); art. 111 (actual art. 122).
} 
que sujetándose a la jerarquía de normas que la acogen ${ }^{68}$. Es lo que podríamos llamar el criterio jerárquico ${ }^{69}$.

Luego afirma que el art. 1, "arranca directa y casi cabalmente del pensamiento cristiano"70. Si esto es así, la Constitución chilena dirige al Estado "el mandato de efectuar una configuración social -en vistas de la igualdad-y de planificar y participar del proceso económico -en vistas de la redistribución-"71. Y para lograr este propósito, en caso que el Estado no cumpla con este propósito, su responsabilidad puede ser exigida a través de los mecanismos políticos y disciplinarios, de modo que el incumplimiento no quede impune ${ }^{72}$.

Con todo, cuando llega al análisis de la operatividad de los derechos fundamentales, Solari reconoce que la Constitución, tratándose de las garantías constitucionales, favorece notoriamente el campo económico, la libre expansión individual y la contención estatal, haciendo suyas las pretensiones del liberalismo económico, en que la actividad estatal, además de limitada se encuentra rigurosamente regulada ${ }^{73}$. Por ello, en la implementación de los derechos sociales señala que si bien se encuentran presentes en la Constitución, lo están de manera precaria y acompañados por garantías económicamente liberales ${ }^{74}$. Aun así, concluye que "es el artículo primero el mejor argumento para decir que la Constitución sí recoge el Estado social de derecho... pues a la finalidad estatal de promover el bien común, corresponde la igual dignidad y los iguales derechos de los hombres. Es decir, la promoción estatal del bien común encuentra su correlato en unas pretensiones subjetivas en orden a la mejor realización posible de las condiciones sociales que permitan a toda persona su mayor realización espiritual y material posible"75.

Atrevida es la propuesta de SolAri, sin embargo, se trata de una postura minoritaria y sobre todo, discutible. Y la discutibilidad no pasa porque discrepe de la instauración en Chile de un Estado social, sino porque los argumentos en que funda su posición chocan con una interpretación sistemática de la Carta o con las variantes de un constitucionalismo más teleológico que originalista.

En cuanto a la colisión con una interpretación sistemática de la Constitución, si bien advierte la pluralidad de fuentes ideológicas que la nutren, relativiza esta tensión y otorga primacía al pensamiento cristiano.

\footnotetext{
68 Solari (1993) 82-83.

69 Este criterio se encuentra aceptado por la doctrina chilena. A modo de ejemplo ZaPATA (1989) 173-174; Evans (1999) 21.

Solari (1993b) 83

Solari (1993b) 84.

Solari (1993b) 88.

Solari (1993b) 105.

Solari (1993b) 108.

Solari (1993b) 110-111.
} 
Además, la Constitución no otorga énfasis a los derechos sociales, opción que se encuentra presente desde la discusión en la Comisión de Estudios y en este punto la influencia de Guzmán es evidente. De ahí que los derechos sociales no cuenten con protección reforzada y devengan en anhelos y propósitos deseables, pero sin exigibilidad directa al deber de actuación que corresponde al Estado ${ }^{76}$.

Asimismo, los postulados de Solari son más cercanos a un constitucionalismo originalista que teleológico, porque defiende el criterio de jerarquía entre las normas y, además, porque afirma que es la filosofía cristiana la que nutre las Bases de la Institucionalidad, conceptos que recoge de los trabajos de la Comisión de Estudios. Conviene recordar en todo caso, que el concepto de dignidad de la persona no es patrimonio único del pensamiento cristiano sino que también es compartido por otras corrientes de pensamiento humanistas y racionalistas ${ }^{77}$.

76 En cuanto al contenido de los derechos sociales, como derechos distintos de los derechos clásicos y, que por tanto, no son derechos en sentido estricto y siendo su exigibilidad relativa, puede verse Martínez (1997) 376 pp., 67-88; Martínez (2008) pp. 275-290., 282-284. Como señalaba, gran importancia en la comprensión de los derechos sociales en la Constitución corresponde a GuZmán quien llegó a afirmar que "la Declaración de Naciones Unidas incurre en un error al que atribuyo no solo importancia doctrinaria, sino consecuencias prácticas considerables. Me refiero a la mezcla indiscriminada que en ella se hace de lo que son propiamente derechos, con los que más bien encierran pretensiones o aspiraciones sociales, que dependen de la capacidad económica de cada sociedad. En un sentido propio y estricto, creo preferible reservar el concepto de derecho a aquellas facultades para cuyo ejercicio, por su titular, solo se requiere que un tercero -sea la autoridad o un particular- no se lo impida o coarte ilegal o arbitrariamente... Distinto es el caso de las pretensiones o aspiraciones sociales, cuya denominación como 'derecho' resulta más bien equívoca, porque sus posibilidades de vigencia dependen de la capacidad económica de cada sociedad... pienso que llamar derecho a lo que son aspiraciones -muy legítimas, nobles y justas-, pero que no siempre se pueden satisfacer aunque haya la mejor voluntad de realizarlo, presenta el riesgo de que todo Estado y todo gobierno sea acusado por ello de no respetar los derechos humanos" (Rojas (1994) 193 pp., 148. (El destacado en original).

77 Como señala Peces - BARba "la dignidad humana en la modernidad y también en este siglo XXI aparece en un contexto intelectual que arranca del tránsito a la modernidad, que ha superado avatares históricos y confrontaciones intelectuales y que se sitúa en lo que llamo el proceso de humanización y de racionalización que acompañan a la persona y a la sociedad, en los diversos procesos de liberación que conducen a la primera a la mayoría de edad y a la segunda a una organización bien ordenada que contribuye al desarrollo de las dimensiones de esa dignidad. La dignidad de la persona y la dignidad de la humanidad son dos aspectos de una misma mentalidad, la del antropocentrismo y de la laicidad, dos coordenadas que encuadran todo el proceso. Cuando reflexionamos sobre la dignidad humana, referencia ética radical, y sobre el compromiso justo que corresponde a las sociedades bien ordenadas, no estamos describiendo una realidad sino un deber ser, en cuyo edificio la dignidad humana es un referente inicial, un punto de partida y también un horizonte final, un punto de llegada. Se puede hablar de un itinerario de la dignidad, de un dinamismo desde el deber ser hasta la realización a través de los valores, de los principios y de los derechos, materia de la ética pública. Por eso la dignidad humana es más un prius que un contenido de la ética pública con vocación de convertirse en moralidad legalizada, o lo que es lo mismo en Derecho positivo justo” Peces-Barba (2004) 82 pp., 63-64. 
Sin embargo, el originalismo genera un problema para la actualización del derecho. Cuando en una Constitución se “juridifican” determinadas cosmovisiones, estas responden a un consenso político históricamente determinado, consenso que es variable por cuanto depende de la evolución de la comunidad, por lo que no es posible extrapolar las opciones de la instancia constitucional y aplicarlas en un momento histórico diferente. Lo que cabe hacer, entonces, es actualizar las decisiones originarias del poder constituyente con el contexto de aplicación de las normas $^{78}$. Por tanto, el riesgo que se corre al permanecer en los fundamentos originales de la Constitución radica en rigidización de las cosmovisiones unido al peligro que supone una petrificación del derecho.

Un adecuado sistema interpretativo debe considerar el carácter evolutivo de la realidad, por ello, deben aplicarse reglas extensivas y flexibles que permitan su adecuación al sentido de las normas en un contexto histórico/espacial determinado. Una mirada de este tipo, no implicaría un desmejoramiento del panorama constitucional o un cuestionamiento a la certeza jurídica, sino que actualiza y sincera la relación entre norma y sociedad.

No obstante la crítica, quisiera insistir en el esfuerzo que realiza Solari para postular que la Constitución recoge el Estado social. Estoy seguro de que tras esa reflexión se esconde el anhelo por contar en Chile con un modelo de sociedad que favorezca una protección cierta de los sectores más empobrecidos de la población. Sin embargo, no ha sido ese el sendero por el que transita la Carta Fundamental, lo que se refleja en el precario desarrollo de los derechos sociales en nuestro sistema constitucional y en algunos fundamentos teóricos que relativizan la importancia de la justicia social ${ }^{79}$.

\section{6) AlgunOS COMENTARIOS FINALES}

Reflexionar sobre el Estado social no es novedoso, ni siquiera original. Ríos de tinta han corrido en otras latitudes tratando esta materia. Y en Chile, debemos avanzar hacia una definición expresa de la sociabilidad del Estado, en que la fórmula Estado social cumpla una función que permita la comprensión y actualización de los postulados del Estado.

En este trabajo sostengo que la Constitución chilena vigente no bebe de un modelo de Estado social, sino que más bien refleja otras propuestas

BASSA (2008) 220 pp., 127-128.

Es cierto que esta última afirmación es discutible, especialmente porque en el actual contexto político y social de nuestro país el tema de los derechos sociales ha generado una movilización social de envergadura. Sin embargo, su escaso desarrollo es uno de los motivos para afirmar la necesidad de una nueva Constitución. 
teóricas, por ejemplo las ideas neoliberales y, sin perjuicio, de la influencia de la filosofía cristiana en el Capítulo relativo a las Bases de la Institucionalidad. De hecho, es esta presencia normativa de las ideas cristianas lo que ha llevado a algunos autores a señalar que en Chile se ha producido una recepción del Estado social. El autor que ha trabajado más detenidamente este asunto es Solari Alliende, propuesta que es digna de ser tenida en cuenta. Sin embargo, se trata de una postura discutible, en que la discutibilidad no pasa porque discrepe de la instauración en Chile un Estado social, sino porque los argumentos en que funda su posición chocan con una interpretación sistemática de la Carta y con las variantes de un constitucionalismo más teleológico que originalista.

Con todo, la materialización de un Estado social es realidad y tarea. No agota su funcionalidad en la declaración semántica si no se proyecta hacia el futuro. Es evidente que, en el devenir de la historia, habrá momentos en que la materialización práctica de su contenido será más accesible que en épocas marcadas por las crisis, sobre todo económicas, sin embargo, la aspiración del Constituyente por generar un estadio en que igualdad material y justicia social, debe ser patrimonio de todos y no de grupos privilegiados.

Si nuestra Constitución llegase a afirmar que el Estado de Chile es un Estado social (y democrático), una definición de esa naturaleza no estará ahí de modo estático sino que habría de suponer una mutación significativa en torno al rol que cabe al Estado en la economía. Y no se trata de una involución a modelos de planificación central. Pero sí poner de relieve que el Estado no solo vela subsidiariamente. Hay sectores de la economía que bien pueden sustraerse de la competencia y no tendrá impacto en los indicadores macroeconómicos y, aseguro, que significará una elevación del PIB, niveles de integración social, desarrollo humano, etc. Y las áreas a las que me refiero son transporte público, regulación eficaz de la industria de farmacias, educación, sistema de salud y previsión social.

Es cierto que todas las esferas sociales pueden ser objeto de análisis económico y que en ellas rija el mercado, sin embargo, esto no significa que mejore la vida en común. Chile está en condiciones de dar un salto al desarrollo, pero este no llegará si no viene acompańado de mejoras en los índices de desarrollo humano. Para que esto sea posible, es necesaria la actuación de un Estado que canalice las demandas sociales, porque en la dialéctica Estado-sociedad, que se decanta hacia una relación horizontal y de interacción recíproca, no serán ni la beneficencia pública ni la virtud ciudadana las que permitirán que se hagan operativos los anhelos del Estado social, sino las políticas efectivas, que suponen la interacción de lo privado y lo público.

No niego la relevancia de la economía de mercado como sistema económico. También valoro la postura que tiende a reducir el tamaño del Estado e ir aligerando su actividad empresarial, como asimismo la rele- 
vancia de las políticas de control de la inflación. Sin embargo, insisto, no todo puede ser mercantilizado, especialmente porque el desarrollo de los derechos sociales no se produce con la pura liberalidad (y asistencialidad). $Y$ es esta una esfera propia y singular en la cual debe desplegar su fuerza un Estado, porque producir una mejora en las condiciones de vida de los menos favorecidos supone implementar políticas sociales en que él puede intervenir de manera directa.

Chile ha sido un precursor en la implementación de un modelo neoliberal, que ha ido ganando fuerza y adeptos en diversas parte del mundo. Los desafíos que se imponen frente al empuje neoliberal son el cuidado de las políticas que protegen el tejido social y no olvidar que como sociedad debemos aspirar a una equiparación en las condiciones de vida de los menos favorecidos. No se trata de una defensa de un sistema de igualdad real, pero sí de promoción y movilidad social de los pobres. Como señala Álvarez-URía, "es preciso supeditar el mercado autorregulado a los imperativos democráticos del Estado social" 80 y frente a esto, en Chile, existe una deuda enorme. El costo social que supuso la implementación de los postulados neoliberales tardó años en repararse y quienes lo asumieron fueron, principalmente, los más pobres. Si bien, en los últimos veinte años ha habido progresos desde la perspectiva del desarrollo humano, ello ha sido posible gracias a la matización de las radicales políticas económicas vigentes durante la dictadura militar ${ }^{81}$.

Si bien es claro que el problema de las desigualdades sociales es un tema complejo, no está claro que, si los individuos son puestos en situación de igualdad de oportunidades, el desarrollo personal y la superación de la pobreza dependan del esfuerzo y empeño de cada uno. Tras ese postulado se esconde un voluntarismo que es desmentido por la realidad.

No obstante, no es suficiente y, dado que los pobres existen y no lo son por opción sino más bien por dificultades en la estructura de la sociedad, es el Estado el encargado de generar políticas redistributivas, porque los criterios mercantiles por sí solos se muestran incapaces de producir mejores resultados en los indicadores de desarrollo humano. Y eso es una opción política. Por tanto, dotar de contenido material a los derechos sociales supone una visión en cuanto al rol del Estado.

Lo mismo que los derechos de primera generación o políticos son conquistas culturales, en que el reconocimiento y respeto de su ejercicio supone una opción ideológica que implica un deber de abstención del poder estatal para favorecer el despliegue de la persona, lo mismo ocurre para los derechos sociales, que por su particular contenido precisan la acción

\footnotetext{
80 Álvarez-Uría, Fernando (2002) “Estado social versus neoliberalismo”. En: Acciones e investigaciones sociales, No 16 , pp. 13-23., p. 23.

81 Ottone, Ernesto; Vergara, Carlos (2007) "La desigualdad social en América Latina y el caso chileno”. En: Estudios Públicos, $N^{o} 108$, pp. 59-91, pp. 80-90.
} 
positiva del Estado. Y la intensidad de la actuación estatal dependerá de la cosmovisión con la cual se construya la sociedad, partiendo de la base de que debe tratarse de una sociedad ordenada, estable y con altos niveles de probidad y transparencia, requisitos que son difíciles de reunir, pero que hacen posible que la 'encarnación' de un Estado social sea una posibilidad y no una utopía o declaración programática de la Constitución.

Por ello comparto lo que señala Díaz: "utopías de ayer son, no siempre pero sí en muchos casos, realidades hoy. Y tampoco es algo 'neutro', o producto del mero azar, que unos derechos hayan logrado, en la historia y/o en la actualidad, plena protección judicial (propiedad) y otros, por el contrario, no la hayan alcanzado (todavía) con ese mismo rigor (por ejemplo, el trabajo)"82. El Estado social puede parecer, en estos momentos un anhelo, pero su incorporación a una nueva Constitución y su implementación, dependerá de las opciones políticas hagamos como comunidad.

\section{Biblografía}

- Abendroth, Wolfgang; Forsthoff, Ernst; Doehring, Karl (1986): "El Estado del derecho democrático y social como proyecto político". En Abendroth, Wolfgang: El Estado Social. Madrid, Centro de Estudios Constitucionales, pp. 9-42.

- Álvarez-Uría, Fernando (2002) "Estado social versus neoliberalismo". En: Acciones e investigaciones sociales, No 16, pp. 13-23.

- Atria, Fernando (2013), Veinte años después, Neoliberalismo con rostro humano, Santiago, Catalonia, pp. 1259 pp.

- Atria, Fernando et al. (2013), El otro modelo, Santiago, Debate, 389 pp.

- Balaguer Callejón, Francisco (2002). "El estado Social y democrático de derecho, alcance y vinculación de la cláusula del Estado Social". En: Monereo Pérez, José Luis: Comentario a la Constitución Socio-Económica de España. Granada. Comenares, pp. 89-113.

- Ballesteros, José Manuel (1980): "Los principios básicos de la Constitución (I): El Estado Social y democrático de Derecho". En: Estudios sobre la Constitución española de 1978. Valencia, Universidad de Valencia. pp. 37-44.

- Bassa Mercado, Jaime (2008) El Estado Constitucional de Derecho. Efecto sobre la Constitución vigente y los derechos sociales, LexisNexis, Santiago, 2008220 pp.

82 Díaz, Elías (2002) “Estado de derecho y legitimidad democrática”. En: Díaz, Elías; ColoMER, José Luis, Estado, justicia y derechos, Madrid, Alianza, pp. 75-104, p 101. 
- Belmar González, Francisco (1986) El Estado Social de Derecho en el constitucionalismo nacional y comparado, Memoria de Prueba para optar al grado de Licenciado en Derecho, Pontificia Universidad Católica de Chile, Santiago. 97 pp.

- Benda, Ernst (2001) "El Estado social de Derecho". En: Benda, Ernst et al., Manual de Derecho Constitucional. 2a edición. Madrid. Marcial Pons, pp. 487-559.

- BöCKenförde, Ernst-Wolfgang (2000) Estudios sobre el Estado de Derecho y la democracia. Madrid. Trotta, 208 pp.

- Carmona Cuenca, Encarnación (2000) El Estado Social de Derecho en la Constitución. Madrid. Consejo Económico y Social. 198 pp.

- Cea Egaña, José Luis (1988) Tratado de la Constitución de 1980, Editorial Jurídica, Santiago, 402 pp.

- Cea Egaña, José Luis (1983) "Garantías constitucionales en el Estado social de derecho". En: Revista chilena de Derecho, vol. 10, No 1, pp. 7-19.

- Cristi, Renato-Ruiz-Tagle, Pablo (2006) La República en Chile, LOM ediciones, Santiago, 2006. $429 \mathrm{pp}$.

- De Cabo Martín, Carlos (1997), Contra el consenso. Estudios sobre el estado constitucional y el constitucionalismo del estado social, México D.F. UNAM, Instituto de investigaciones jurídicas, $393 \mathrm{pp}$.

- DíAz, Elías (2002) "Estado de derecho y legitimidad democrática". En: Díaz, Elías; Colomer, José Luis, Estado, justicia y derechos, Madrid, Alianza, pp. 75-104.

- Evans de la Cuadra, Enrique (1999) Los derechos constitucionales, tomo I, 2a edición, Editorial Jurídica, Santiago, 1999,.

- Ferrajoli, Luigi (2011), Principia Iuris, vol. 2. Teoría de la democracia, Madrid. Trotta. $676 \mathrm{pp}$.

- Fuentes Saavedra, Claudio (2012) El Pacto. Santiago. Ediciones Universidad Diego Portales.

- García-Pelayo, Manuel (1989) Las transformaciones del Estado contemporáneo. $2^{\text {a }}$ edición. Madrid: Alianza. 224 pp.

- Garrorena Morales, Ángel (1987) El Estado español como Estado social y democrático de Derecho, El Estado español como Estado social y democrático de Derecho. Madrid. Tecnos. 254 pp.

- Gómez, Jesús María (1995) "El Estado del bienestar y el reto de la solidaridad". En: Anales de estudios económicos y empresariales, $\mathrm{N}^{\circ} 10$ Universidad de Valladolid, pp. 255-276.

- González Moreno, Beatriz (2002) El Estado Social. Naturaleza jurídica y estructura de los derechos sociales. Madrid. CivitasUniversidad de Vigo. 263 pp.

- Häberle, Peter (2002) Pluralismo y constitución. Madrid. Tecnos. 295 pp. 
- Heller, Hermann (1985): “Europa y el fascismo”. En: Heller, Hermann (1985): Escritos Políticos. Madrid, Alianza, pp. 21-132.

- Heller, Hermann (1985): “¿Estado de Derecho o Dictadura?". En: Heller, Hermann: Escritos Politicos. Madrid, Alianza, pp. 283-301.

- Heller, Hermann (2004 a) Las ideas politicas contemporáneas. Granada, Comenares. 153 pp.

- Heller, Hermann (2004 b) Teoría del Estado. Granada, Comenares. $330 \mathrm{pp}$.

- HobBes, Thomas (1999) Tratado sobre el ciudadano. Traducción de Joaquín Rodríguez. Madrid, Trotta. 205 pp.

- Jimena Quesada, Luis (1997) La Europa Social y democrática de derecho, Madrid, Dykinson. 370 pp.

- Jordán Díaz, Tomás (2006): "La protección de los derechos sociales: modelos comparados de tutela jurisprudencial (España y Chile)". En: Colección de Investigaciones Juridicas, $\mathrm{N}^{\circ} 10$. Santiago. Facultad de Derecho, Universidad Alberto Hurtado. 502 pp.

- Lovera Parmo, Domingo (2014), Derecho a la protesta en la Constitución de 1980 (de 1989 y de 2005), inédito, pp. 1-15.

- Martínez de Pisón, José (1994) "La crítica neoliberal al Estado Social. Un resumen y una valoración”. En: Doxa, N 15-16, pp. 243-270.

- Martínez Estay, José Ignacio (1997) Jurisprudencia Constitucional Española sobre Derechos Sociales. Barcelona, CEDECS. 376 pp.

- Martínez Estay, José Ignacio (2008) "Los derechos sociales: una reflexión a propósito de la sentencia rol 976 del Tribunal Constitucional". En: Nomos No 2, pp. 275-290.

- Mayol, Alberto (2012), El derrumbe del modelo santiago, LOM, $166 \mathrm{pp}$.

- Mayol, Alberto (2012), No al lucro, Santiago, Debate, pp. 392 pp.

- Monereo-Pérez, José Luis (2004): "Estudio preliminar. La teoría político-jurídica de Hermann Heller”. En: Heller, Hermann: Teoría del Estado, Granada, Comares. I-XIL pp..

- Nino, Carlos Santiago (1997) La constitución de la democracia deliberativa. Barcelona, Gedisa, 303 pp.

- Ojeda Marín, Alfonso (1990) El contenido económico de las Constituciones modernas. Madrid. Instituto de Estudios Fiscales. 328 pp.

- OECD (2014), Society at a Glance 2014: OECD Social Indicators, OECD Publishing. Disponible en http://dx.doi.org/10.1787/soc_ glance-2014-en [última visita 27 de marzo de 2014], 143 pp.

- Offe, Claus (1988) Partidos politicos y nuevos movimientos sociales. Madrid. Editorial Sistema. 265 pp.

- Offe, Claus (1988) Contradicciones en el Estado del Bienestar. Madrid. Alianza. 309 pp.

- Ojeda Marín, Alfonso (1993) Estado social y crisis económica. Madrid. Editorial Complutense. 124 pp. 
- Ottone, Ernesto; Vergara, Carlos (2007) "La desigualdad social en América Latina y el caso chileno”. En: Estudios Públicos, No 108, pp. 59- 91.

- Palma González, Eric (2002) “¿Gobierno portaliano o gobierno conservador autoritario?: de los mecanismos constitucionales para garantizar la eficacia del ejercicio del poder en la constitución de 1833”. En: Revista de Derecho (Valdivia), vol. XIII, pp. 45-64.

- Peces-Barba Martínez, Gregorio (2004) La dignidad de la persona desde la filosofia del derecho, Dykinson, Madrid, $82 \mathrm{pp}$.

- Pérez-Luño, Antonio (2004) Los derechos fundamentales. $8^{\text {a }}$ edición. Madrid, Tecnos. 233 pp.

- Pisarello, Gerardo (2001) "Del Estado Social legislativo al Estado Social constitucional: por una protección compleja de los derecho". En : Isonomía $\mathrm{N}^{\circ} 15$, pp. 81-107.

- Programme for International Student Assessment (2013), PISA 2012 Results in Focus. OECD Publishing. Disponible en http:// www.oecd.org/pisa/keyfindings/pisa-2012-results-overview.pdf [última visita 27 de marzo de 2014] $32 \mathrm{pp}$.

- Programa de Gobierno Michelle Bachelet [2014-2018] (2013). Disponible en http://michellebachelet.cl/programa/ [fecha de visita, 26 de marzo de 2014].

- Programa de las Naciones Unidas para el Desarrollo (2013), Informe sobre Desarrollo Humano 2013. El ascenso del Sur: Progreso humano en un mundo diverso. Nueva York. PNUD Disponible en http://www.undp.org/content/dam/undp/library/corporate/ HDR/2013GlobalHDR/Spanish/HDR2013\%20Report $\% 20$ Spanish.pdf [última visita 27 de marzo de 2014] 216 pp.

- Quintana Benavides, Augusto (1989) "El principio de solidaridad en la Constitución”. En: Revista Chilena de Derecho, vol. 20, No 2-3, pp. 635-638.

- Ritter, Gerhard (1991), El estado social, su origen y desarrollo en una comparación internacional, Madrid, Centro de Publicaciones Ministerio de Trabajo y Seguridad Social, 300 pp.

- Rojas Sánchez, Gonzalo (1996) Derecho Político. Apuntes de las clases del profesor Jaime Guzmán Errázuriz, Ediciones Universidad Católica de Chile, Santiago. 193 pp.

- Rosanvallon, Pierre (1981) La crise de l'Etat-providence. Paris. Editions du Seuil. 194 pp.

- Roosevelt, Franklin (1999) Great Speeches, New York, Dover Publications. 176 pp.

- Rubio Lara, María Josefa (1991) La formación del Estado Social. Colección. Madrid. Tesis doctorales Ministerio de Trabajo y Seguridad Social. 491 pp. 
- Salazar, Gabriel (1999) Historia contemporánea de Chile, tomo I, LOM ediciones, Santiago, 1999. 3 I I pp.

- Serra, Francisco (1991) "El futuro del Estado social". En: Olivas, Enrique: Problemas de legitimación en el estado social. Madrid. Trotta, pp. 165-176.

- Silva Gallinato, María Pía (2012) "El Estado social de derecho en la Constitución chilena". En: Aguillar Cavallo, Gonzalo, Derechos económicos, sociales y culturales en el orden constitucional chileno, Santiago, Librotecnia, pp. 29-48.

- Solari Alliende, Enzo (1997) "Para un concepto del Estado social de Derecho". En: Revista de Ciencias Sociales, No 42, 1997, pp. 11104.

- Solari Alliende, Enzo (1993a) "Recepción en Chile del Estado Social de Derecho". En: Revista chilena de Derecho, vol. 20, No 2-3, pp. 333-344.

- Solari Alliende, Enzo (1993b) El Estado social de Derecho y su recepción en Chile, Memoria de Prueba para optar al grado de Licenciado en Ciencias Jurídicas y Sociales, Pontificia Universidad Católica de Valparaíso, Valparaíso, 1993. 122 pp.

- Varela del Solar, Jorge Luis (1984) "Estudio sobre el artículo primero de la Constitución de 1980". En: Revista chilena de Derecho, vol. 11, No 2-3, pp. 385-402.

- Varela del Solar, Jorge Luis (1989) "Subsidiariedad, Orden Público Económico y Seguridad Nacional en la Constitución de 1980" En: Revista chilena de Derecho, vol. 16, No 2, 379-390.

- Viera Álvarez, Christian (2013) Libre iniciativa económica y Estado Socials Santiago, Thomson Reuters. 417 pp.

- Zapata Larraín, Patricio (1989) "La interpretación de la Constitución”. En: Revista Chilena de Derecho, vol. 17, No 1, pp. 161-177. 